\title{
Correction to: The P/N (Positive-to-Negative Links) Ratio in Complex Networks-A Promising In Silico Biomarker for Detecting Changes Occurring in the Human Microbiome
}

\author{
Zhanshan (Sam) $\mathrm{Ma}^{1}$
}

Published online: 13 November 2017

(C) Springer Science+Business Media, LLC, part of Springer Nature 2017

\section{Correction to: Microb Ecol (2017)}

https://doi.org/10.1007/s00248-017-1079-7

The original version of this article unfortunately contained a missing image. The flowchart was not captured in PDF version. The original article was corrected.

The online version of the original article can be found at https://oi.org/ 10.1007/s00248-017-1079-7

Zhanshan (Sam) Ma

ma@vandals.uidaho.edu

1 Computational Biology and Medical Ecology Lab, State Key Lab of Genetic Resources and Evolution, Kunming Institute of Zoology,

Chinese Academy of Sciences, Kunming 650223, China 